\title{
SINGLE-BEAM BATHYMETRY DATA NEAR KOTLIK, ALASKA, COLLECTED JULY 2021
}

Jacquelyn R. Overbeck, Jessica E. Christian, and Richard M. Buzard

Raw Data File 2021-14

This report has not been reviewed for technical content or for conformity to the editorial standards of DGGS.

2021

STATE OF ALASKA

DEPARTMENT OF NATURAL RESOURCES

DIVISION OF GEOLOGICAL \& GEOPHYSICAL SURVEYS
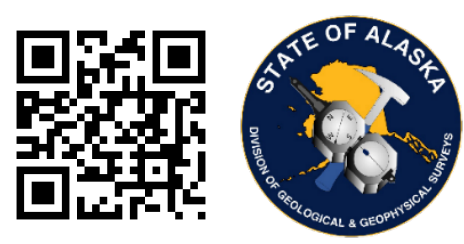


\section{STATE OF ALASKA}

Mike Dunleavy, Governor

\section{DEPARTMENT OF NATURAL RESOURCES}

Corri A. Feige, Commissioner

\section{DIVISION OF GEOLOGICAL \& GEOPHYSICAL SURVEYS}

Steve Masterman, State Geologist \& Director

Publications produced by the Division of Geological \& Geophysical Surveys are available to download from the DGGS website (dggs.alaska.gov). Publications on hard-copy or digital media can be examined or purchased in the Fairbanks office:

\section{Alaska Division of Geological \& Geophysical Surveys (DGGS) \\ 3354 College Road | Fairbanks, Alaska 99709-3707 \\ Phone: 907.451 .5010 | Fax 907.451.5050 \\ dggspubs@alaska.gov | dggs.alaska.gov}

DGGS publications are also available at:

Alaska State Library, Historical

Collections \& Talking Book Center

395 Whittier Street

Juneau, Alaska 99801

Alaska Resource Library and

Information Services (ARLIS)

3150 C Street, Suite 100

Anchorage, Alaska 99503

\section{Suggested citation:}

Overbeck, J.R., Christian, J.E., and Buzard, R.M., 2021, Single-beam bathymetry data near Kotlik, Alaska, collected July 2021: Alaska Division of Geological \& Geophysical Surveys Raw Data File 2021-14, 6 p.

https://doi.org/10.14509/30764

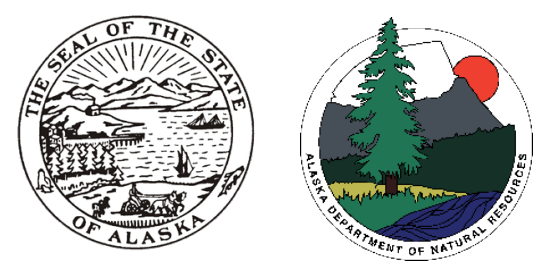





\section{SINGLE-BEAM BATHYMETRY DATA NEAR KOTLIK, ALASKA, COLLECTED JULY 2021}

Jacquelyn R. Overbeck ${ }^{1}$, Jessica E. Christian ${ }^{2}$, and Richard M. Buzard ${ }^{1}$

\section{INTRODUCTION}

The State of Alaska Division of Geological \& Geophysical Surveys (DGGS) used a M2Ocean Hydroball-an integrated echosounder, Global Navigation Satellite System (GNSS) antenna, and inclinometer - to collect bathymetric transects near Kotlik on July 7 and 9, 2021 (fig. 1). The goal of the survey is to provide bathymetric data for the purpose of assessing coastal hazards and for river erosion studies. Bathymetric data were corrected using a coincident water level time series referenced to a vertical datum using GNSS survey. The bathymetric data were processed using CIDCO DepthStar. This data collection is being released as a Raw Data File with an open end-user license. All files can be downloaded from the DGGS website at https://doi.org/10.14509/30764.

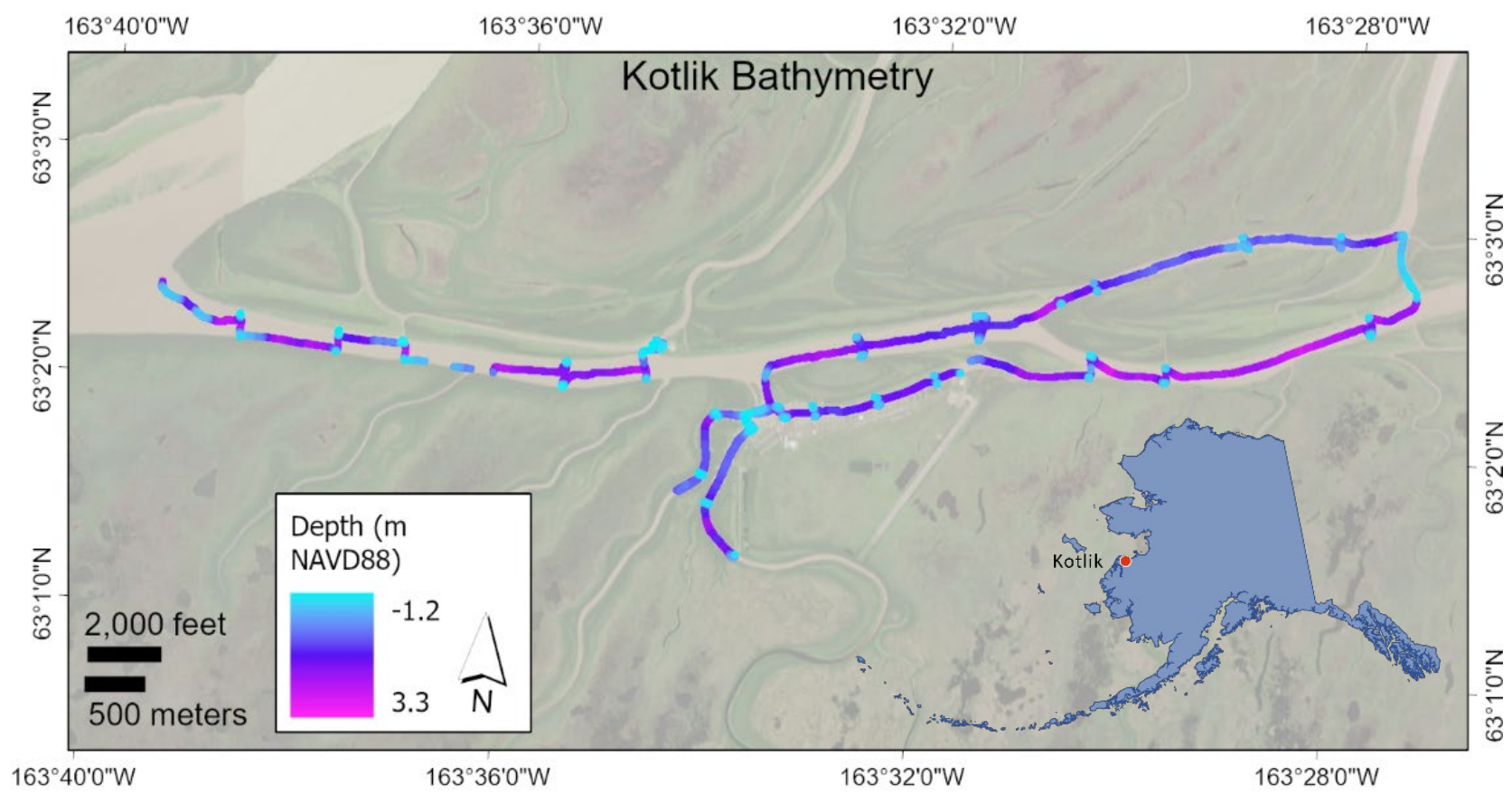

Figure 1. Map of single-beam bathymetry product boundaries for Kotlik.

\section{LIST OF DELIVERABLES}

- Point Elevation Text File

- Metadata

\footnotetext{
${ }^{1}$ Alaska Division of Geological \& Geophysical Surveys, 3354 College Road, Fairbanks, AK 99709

${ }^{2}$ University of Alaska Fairbanks Arctic Coastal Geoscience Lab, P.O. Box 755780, Fairbanks, AK 99775.
} 


\section{MISSION PLAN}

\section{Bathymetric Survey Details}

DGGS used a M20cean Hydroball bathymetric sensor, which is composed of a Tallysman TW3972 GNSS antenna, Imagenex 852 single-beam echosounder, and Honeywell HMR3000 inclinometer. The Hydroball was placed in a catamaran configuration and towed behind a small skiff at speeds below 4 knots (fig. 2). A total of 21.7 kilometers of river were surveyed, which included 25 cross-river transects.

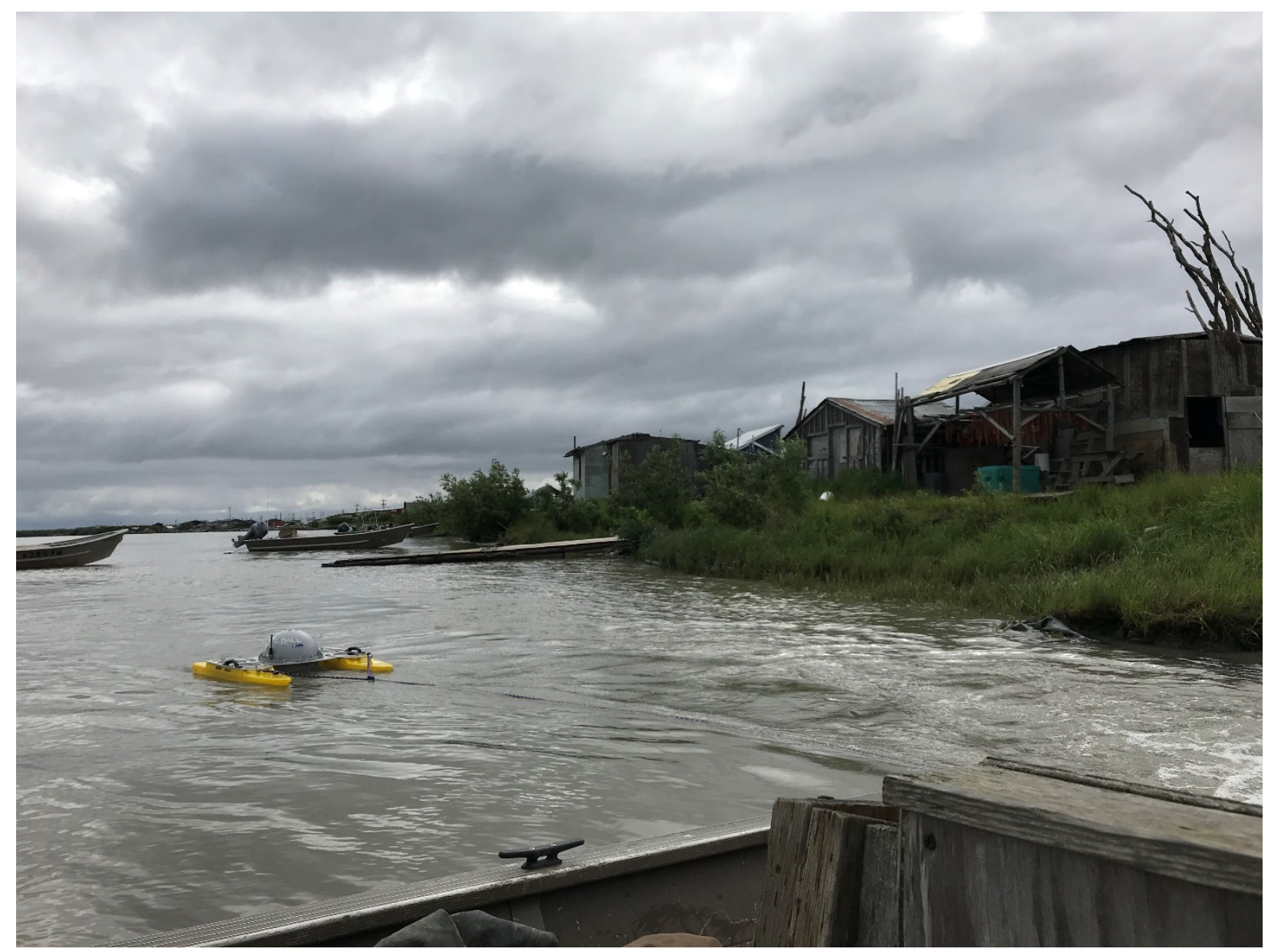

Figure 2. Hydroball catamaran towing configuration.

\section{Weather and Towing Conditions}

The survey was completed on July 7 and 9, 2021, from 9:42 AM to 3:00 PM and 10:50 AM to 12:30 PM AKDT, respectively. During the survey, the operator started and stopped collection once each day. The weather throughout the survey was fair with scattered clouds and no rain. No abnormalities were observed during collection. 


\section{SURVEY AND PROCESSING REPORT}

\section{Ground Survey Details}

DGGS set up a GNSS base station using the Trimble R10 receiver sampling at $1 \mathrm{~Hz}$. The base was installed over a temporary benchmark of unknown position. This provided real-time kinematic (RTK) corrections to the Trimble R8s GNSS receiver (ground rover). DGGS measured the height of a water level sensor with the R8s at installation. The corrected base position was later derived using the Online Positioning User Service (found at http://www.ngs.noaa.gov/OPUS/). The R8s position was updated using post-processing kinematic (PPK) corrections in Trimble Business Center.

\section{Water Level Survey Details}

A Solinst Levelogger was installed at Kotlik during the bathymetric survey to provide water level corrections. The Levelogger was configured to collect at 15-minute intervals and installed in a plastic bucket stilling well placed on the seafloor of the Kotlik River near the community water intake pipe (fig. 3). Barometric data were downloaded from Iowa State University Environmental Mesonet website (http://mesonet.agron.iastate.edu/request/download.phtml?network=AK ASOS) from the airport at Emmonak (airport code PAEM) for the bathymetric survey duration. Water level data were extracted from the Levelogger using Solinst Levelogger 5 Series software and exported as .csv files. Matching of the collection time, as well as a barometric compensation of the water surface, were completed in Matlab. A linear interpolation was applied to the barometric data to match the Levelogger time series and a multiplying correction was used to convert $1 \mathrm{kPa}$ to $0.101972 \mathrm{~m}$ depth. The corrected water level time series was converted to coordinated universal time (UTC) and exported as a tid file for ingestion in DepthStar.
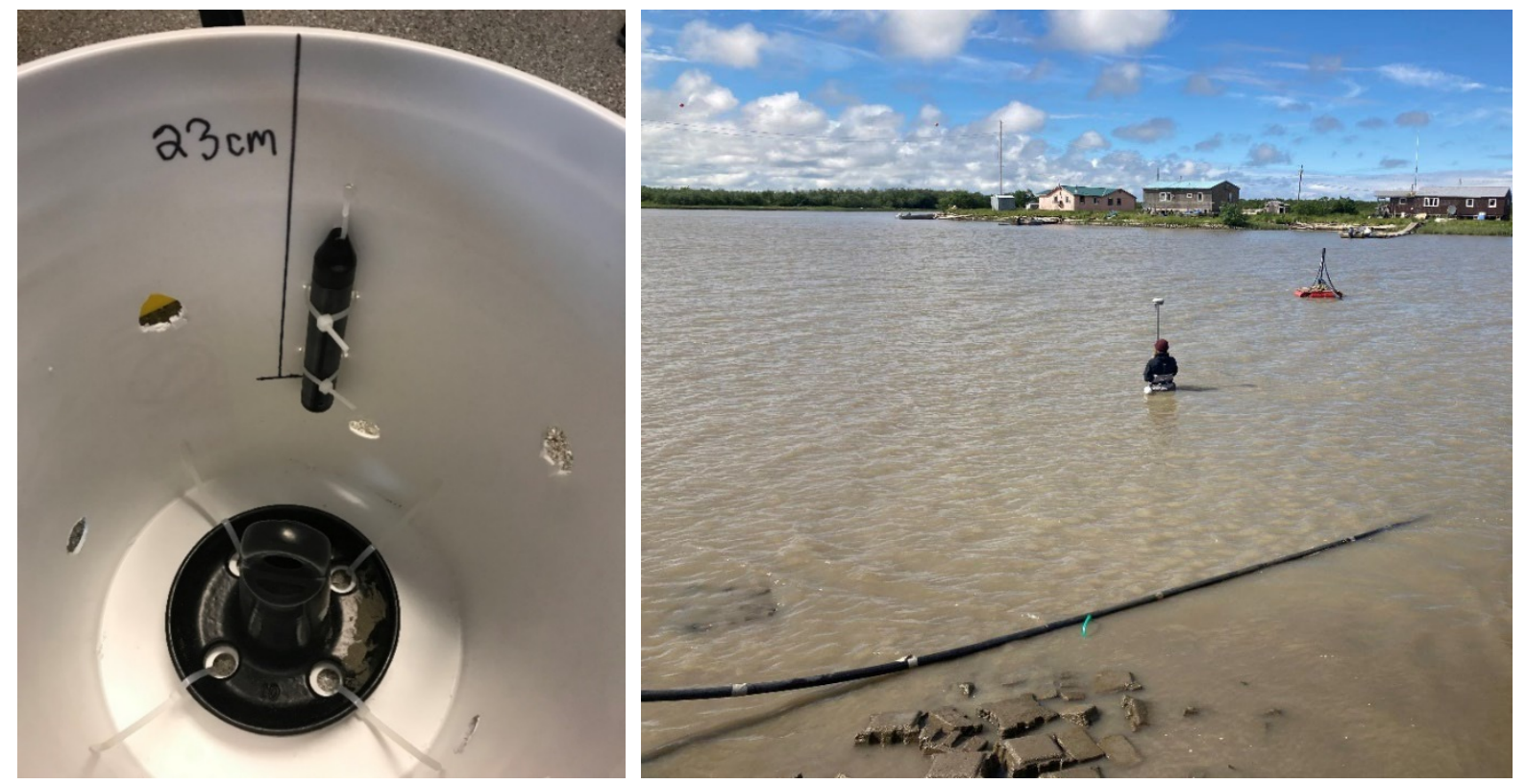

Figure 3. Solinst Levelogger stilling well configuration (left) and water level sensor location at community water intake (right).

\section{Bathymetry Survey Details}


The Hydroball produces three files for export: .dev, .bin, and 0.852, which are directly imported into CIDCO DepthStar software. Processing steps are to input survey settings, upload dev and tid files, filter depth returns based on minimum depth and moving average thresholds, manually add and remove points based on visual quality, georeference the hydroball position, and export as .txt. Since the catamaran configuration was used during the survey, a draft correction $0.115 \mathrm{~m}$ and a and a GNSS antenna position reference point to echo sounder acoustic center correction of $0.364 \mathrm{~m}$ were applied. The minimum depth (sonar threshold) was set at $0.7 \mathrm{~m}$ and moving average threshold at $0.5 \mathrm{~m}$. Data were georeferenced using the water level reference survey (WLRS) sounding reduction method with a sound velocity of $1450 \mathrm{~m} / \mathrm{s}$, which is the value used for fresh water. The position source was kept raw.

\section{ACCURACY REPORT}

\section{Coordinate System and Datum}

All data are processed and delivered in NAD83 (2011) UTM Zone 3N and vertical datum NAVD88 (GEOID12B).

\section{Horizontal Accuracy}

Horizontal accuracy was not evaluated.

\section{Vertical Accuracy}

A quality control report was run in DepthStar to compute vertical offsets of overlapping points (intersections) throughout the survey. There were 55 intersections in total with an offset range between $0.000 \mathrm{~m}$ and $0.222 \mathrm{~m}$ and a vertical accuracy of $0.138 \mathrm{~m}$ at the $95^{\text {th }}$ percentile (table 1 and fig. 4).

Table 1. Survey intersection locations and vertical separation.

\begin{tabular}{|c|c|c|}
\hline Longitude & Latitude & $\begin{array}{c}\text { Vertical Separation } \\
(\mathbf{m})\end{array}$ \\
\hline-163.579095 & 63.03618050 & 0.006 \\
\hline-163.579095 & 63.03618010 & 0.088 \\
\hline-163.579095 & 63.03617975 & 0.037 \\
\hline-163.578966 & 63.03582310 & 0.009 \\
\hline-163.568781 & 63.02906164 & 0.033 \\
\hline-163.567965 & 63.02615973 & 0.048 \\
\hline-163.567917 & 63.02655327 & 0.018 \\
\hline-163.567788 & 63.02679202 & 0.040 \\
\hline-163.567713 & 63.02687028 & 0.025 \\
\hline-163.567384 & 63.02718572 & 0.023 \\
\hline-163.567055 & 63.02750528 & 0.010 \\
\hline-163.566855 & 63.02769947 & 0.140 \\
\hline-163.566217 & 63.02833357 & 0.106 \\
\hline
\end{tabular}




\begin{tabular}{|c|c|c|}
\hline Longitude & Latitude & $\begin{array}{c}\text { Vertical Separation } \\
(\mathbf{m})\end{array}$ \\
\hline-163.566095 & 63.02439588 & 0.004 \\
\hline-163.565531 & 63.02413133 & 0.002 \\
\hline-163.564361 & 63.02363935 & 0.125 \\
\hline-163.563930 & 63.02345613 & 0.110 \\
\hline-163.562594 & 63.03299861 & 0.069 \\
\hline-163.562565 & 63.03310529 & 0.032 \\
\hline-163.561652 & 63.03359540 & 0.017 \\
\hline-163.559230 & 63.03389276 & 0.004 \\
\hline-163.559157 & 63.03390730 & 0.003 \\
\hline-163.558797 & 63.03395591 & 0.009 \\
\hline-163.558257 & 63.03400260 & 0.058 \\
\hline-163.558008 & 63.03409160 & 0.019 \\
\hline-163.557787 & 63.03402143 & 0.028 \\
\hline-163.557669 & 63.03417356 & 0.114 \\
\hline-163.557532 & 63.03421230 & 0.222 \\
\hline-163.557203 & 63.03414001 & 0.053 \\
\hline-163.557075 & 63.03396226 & 0.077 \\
\hline-163.557034 & 63.03395887 & 0.009 \\
\hline-163.556986 & 63.03389334 & 0.114 \\
\hline-163.556895 & 63.03377085 & 0.031 \\
\hline-163.556787 & 63.03374611 & 0.069 \\
\hline-163.556640 & 63.03358171 & 0.047 \\
\hline-163.556612 & 63.03353473 & 0.005 \\
\hline-163.556529 & 63.03344855 & 0.042 \\
\hline-163.556312 & 63.03343972 & 0.022 \\
\hline-163.555974 & 63.03340467 & 0.029 \\
\hline-163.555534 & 63.03368286 & 0.009 \\
\hline-163.555526 & 63.03368491 & 0.092 \\
\hline-163.555516 & 63.03368735 & 0.054 \\
\hline-163.555512 & 63.03368816 & 0.018 \\
\hline-163.555483 & 63.03369613 & 0.021 \\
\hline-163.551485 & 63.03416827 & 0.002 \\
\hline-163.545470 & 63.03969866 & 0.138 \\
\hline-163.541667 & 63.03536208 & 0.026 \\
\hline-163.526145 & 63.04117733 & 0.010 \\
\hline-163.513042 & 63.04315463 & 0.001 \\
\hline-163.513042 & 63.04315467 & 0.010 \\
\hline-163.513042 & 63.04315450 & 0.000 \\
\hline-163.513042 & 63.04315450 & 0.000 \\
\hline-163.495361 & 63.03896938 & 0.157 \\
\hline-163.484174 & 63.04882005 & 0.018 \\
\hline
\end{tabular}




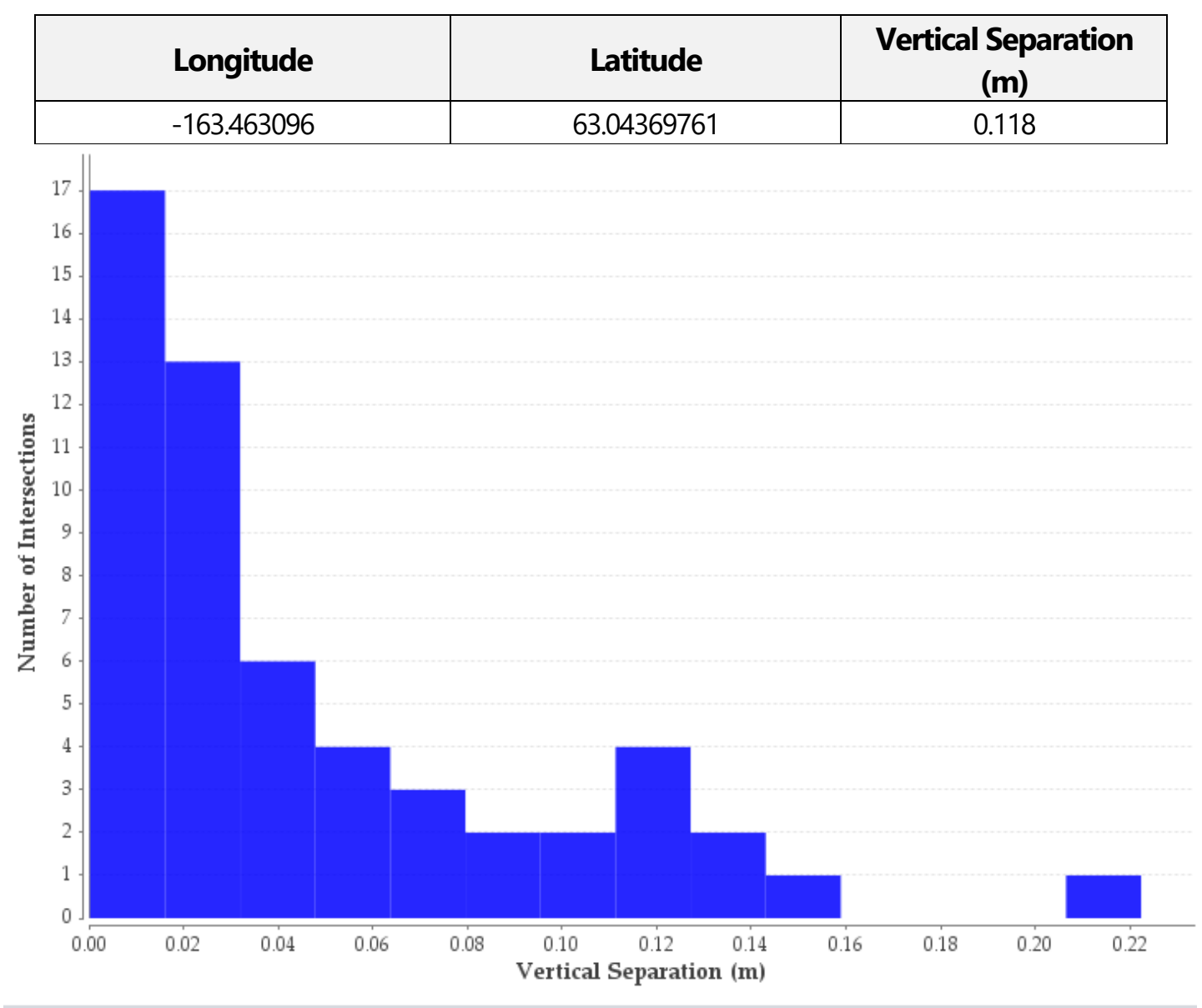

Min: $0.000 \mathrm{~m}$ | 1st Quartile: $0.009 \mathrm{~m}$ | Median: $0.028 \mathrm{~m}$ | 3rd Quartile: $0.069 \mathrm{~m}$ | Max: $0.222 \mathrm{~m}$

Figure 4. Histogram and summary statistics of vertical separation between intersecting survey points.

\section{Data Consistency and Completeness}

The bathymetry data have been visually inspected for data errors such as false returns. Erroneous data were removed in the data processing, which may lead to gaps between and along transects. Additional data errors may exist due to increased wave activity during segments of surveys, however, these errors were not evaluated or removed.

\section{ACKNOWLEDGMENTS}

This work was funded by the Bureau of Indian Affairs Tribal Resilience Program through a collaborative project with the Native Village of Bill Moore's Slough. We especially thank the Indian General Assistance Program for the Native Village of Bill Moore's Slough for assistance in carrying out the survey. 